\title{
Communication Competence in Mathematics: Analysis of the Evolution of Calculus Student Skills throughout their Freshmen Year
}

\author{
Marta Graciela Caligaris, María Elena Schivo and María Rosa Romiti \\ Facultad Regional San Nicolás - Universidad Tecnológica Nacional \\ San Nicolás, Argentina
}

\begin{abstract}
The objective of this paper is to analyze if freshmen evolve throughout the year in the communication of a statement, result or mathematical text considering three semiotic registers of representation, the natural, the graphic and the symbolic ones. This paper presents a study carried out throughout the school year 2018 on the performance of students in the communication competence in Mathematics. The issues on calculus in one variable, on the specialties of Industrial Engineering and Electronic Engineering at the Facultad Regional San Nicolás, Universidad Tecnológica Nacional (FRSN-UTN) from Argentina, were considered. For the collection of data associated with the students' productions, four assessments were carried out. Among other skills, Engineering students must be able to effectively use and articulate the external representations needed to communicate mathematical ideas: spoken language, written symbols, drawings or physical objects. Although during the first semester the results were alarming in the three registers of representation, mainly for Industrial Engineering, it can be seen that during the second semester the number of unsatisfactory starts to decrease, finishing both courses with small differences.
\end{abstract}

Keywords: Competences; Communication; Semiotic registers.

\section{Introduction}

In 1988 the Federal Council of Deans of Engineering of the Argentine Republic (Consejo Federal de Decanos de Ingeniería, CONFEDI, in Spanish) was formed with the aim of creating a space to discuss and promote solutions to university problems raised in the Academic Engineering Units.

In recent years, its role in the quality of training, its cooperative work in the different academic units, and its connection with other countries have been fundamental, placing Argentina as a benchmark in the region. 
In November 2013, in the city of Valparaíso, the General Assembly of the IberoAmerican Association of Engineering Education Institutions (Asociación Iberoamericana de Instituciones de Enseñanza de la Ingeniería, ASIBEI, in Spanish) adopts as its own the synthesis of generic competences agreed by CONFEDI, giving rise to the "Declaration of Valparaíso" on generic competences of graduates of the Ibero-American engineer.

The old paradigm of training professionals based on teaching as a simple scheme of knowledge transfer that the student will eventually be able to abstract, articulate and apply effectively, has been losing space in today's reality. Learning requires effective use of personal communication skills. The idea that learning is a lifelong endeavor necessitates special attention to the role of interpersonal communication in making learning efficient, meaningful, and long-lasting (Deveci, 2019).

The current vision of society proposes to see the university graduates as competent beings (with a set of competences) capable of exercising their profession in the reality that surrounds them (Giordano Lerena, 2018). Competency is understood as the ability to effectively articulate a set of mental structures or values, allowing different knowledge to be made available in a specific context in order to resolve professional situations. Competencies refer to complex and integrated skills, related to knowledge that is linked to know-how, among other things (Giordano Lerena, 2016). Competencies encompass knowledge, skills, and attitudes.

The CONFEDI proposes a scheme with certain specific competences of each specialty and ten general graduation competences, five technological and five social, political and attitudinal. These competencies can also be developed and perfected outside the academic environment, in the labor field, for example.

There is no doubt about the need of teaching technical skills, but technical competences are not enough in the actual world. Nevertheless, the suitability of teaching soft skills, and the way to do it, is still being discussed (Kumar, Hsiao, 2007; Davis, 2010; Palma, de los Ríos, Miñán, 2011; Cubero, 2017; Szilárda, Benedeka, Ionel-Cioca, 2018).

The proposed social, political and attitudinal competencies are:

- Performing effectively in work teams.

- Communicating effectively.

- Acting with ethics, professional responsibility and social commitment, considering the economic, social and environmental impact of their activity in the local and global context.

- Learning in a continuous and autonomous way.

- Acting with an entrepreneurial spirit.

The competence to communicate effectively requires the effective articulation of diverse capacities, among which is to select communication strategies according to the objectives and the partners, agree on meanings in the context of exchange, and to produce and interpret technical texts. This ability implies, among other 
things, being able to express themselves briefly, clearly and precisely, both orally and in writing, be able to use and articulate correctly different languages (formal, graphic and natural), effectively communicate problems related to the profession, to people outside of it.

Various writing exercises should be incorporated into the engineering courses as a strategy to enhance the communication skills of the students as well as their learning experience. Carefully designed activities can help in achieving the learning outcomes demanded by the discipline (Nadeem, Blumenstein, BiglariAbhari, 2018).

The development of competencies is a process that must start on the first day of classes. The competences should be distributed throughout the curriculum and it is the responsibility of all teachers to provide input on them, teach them at the level that corresponds to their subjects, as well as assess them.

Study habits of first-year university students and the way they communicate with each other and their professors (Gallardo-Echenique, Bullen, M., MarquésMolías, 2016), have been reported.

This paper presents a study carried out throughout the school year 2018 on the performance of freshmen in the communication competence in Mathematics. The issues on calculus in one variable, on the specialties of Industrial Engineering and Electronic Engineering at the Facultad Regional San Nicolás, Universidad Tecnológica Nacional (FRSN-UTN) from Argentina, were considered. Only those students who completed the course were taken into account in the presented results, with 21 corresponding to the specialty of Electronic Engineering and 15 belonging to one course of Industrial Engineering. These two specialties were chosen due to their varied population, since the students entering Electronic Engineering come, initially, in 54\%, from high schools of technical modality, while those who chose Industrial Engineering have completed their high school with non-technical modality.

The objective of this paper is to analyze if students evolve throughout the year in the communication of a statement, result or mathematical text considering three semiotic registers of representation, the natural, the graphic, and the symbolic ones.

In fact, the content to be communicated was not an obstacle, the performance of the students was assessed in four individual activities that involved simple concepts addressed in the high school and treated and evaluated in the introductory course to the FRSN-UTN for the first assessment and developed as contents of the subject, in the remaining three.

It is worth noting that during the development of the units, a reinforcement work was carried out in the communication in the three registers, natural, graphic and symbolic, with activities similar to those assessed later. Then, before each definition or property taught, they were asked to explain them with their 
own words, to represent them graphically or to write them in symbols, as the case may be.

\section{Registers of semiotic representation}

Among other skills, engineering students must be able to effectively use and articulate the external representations needed to communicate mathematical ideas: spoken language, written symbols, drawings and graphs. The learning of Mathematics is an appropriate field of study to analyze certain cognitive activities such as text comprehension, conceptualization, reasoning or problem solving.

Mathematical concepts can be represented in some or all of the possible forms of representation, taking the form of spoken language, written symbols, drawings or physical objects (Díaz, 2009). The ability to represent those concepts in a variety of ways shows "understanding". The outcomes of learning may include descriptions, classifications, representations and more (Gynnild, 2016). Students feel they have learned when they feel the essence of an idea has been captured (Sierpinska, 2013).

Mathematical processing always involves substituting some semiotic representation for another. The representations are as important as their transformation. Unlike the other areas of scientific knowledge, signs and semiotic representation transformation are at the heart of mathematical activity (Duval, 2006).

To facilitate learning with multiple representations, visual representation of data and ideas have been used as cognitive tools in a recent study (Gebre, 2018).

Duval (2004) defines as register of semiotic representation every semiotic system that allows three cognitive activities:

1) The presence of an identifiable representation, that is, recognizable as an external representation of something in a certain system such as a graphic, a symbol, a phrase, among others.

2) The treatment of a representation that is the transformation of the representation within the same register where it has been formulated.

3) The conversion of a representation that is the transformation of the representation into another representation of another register in which all or part of the meaning of the initial representation is preserved.

In Mathematics, semiotic representations are important both for the purposes of communication and for the development of the Mathematical activity.

The registers considered for this experience are those that have been defined in previous works (Romiti, Sgreccia, Caligaris, 2012):

Natural register. It is associated to the mother tongue, the first language that a person learns and uses as a habitual mode of expression in the different areas of ordinary life, to make descriptions, explanations, arguments, deductions, with the aim of communicating. It can be used orally or in writing, considering the latter in the present work. 
Graphical register. It contemplates representations of sets on a coordinate line, in a system of orthogonal Cartesian coordinates and informal sketches leaving aside a reference system.

Symbolic register. Mathematics is supported by a formal symbolic language that follows a series of own conventions. The symbols can be considered objects with their own value and represent a concept, an operation, a Mathematical entity according to certain rules. The symbols can involve a single letter or several letters and numbers. This work considers the symbolic register composed of two parts:

Symbolic of procedural predominance: one in which the student must apply, to solve a problem, simple or routine strategies.

Symbolic of conceptual predominance: that in which the student needs to know and handle the mathematical symbols of definitions or properties. In this type of activities, it is necessary to work with greater rigor, although in general algebraic procedures are applied in search of solutions. It is an instance in which a more formal, abstract and understanding thought than the previous one is involved. This register was the one considered in the experience.

\section{Methodology}

The evaluation during the development of the course consists in the continuous evaluation of the learning, but also in the revision of the teaching process. In fact, carrying out continuous evaluation allows professors to improve the teaching process, since they are still in time to reorient the methodologies used to achieve the desired purposes (Pimienta Prieto, 2012).

For the collection of data associated with the students' productions in the four assessments carried out, self-administered open-ended questionnaires were designed, since they were provided directly to the students of both specialties, who answered them without intermediaries (Hernández Sampieri, Fernández Collado \& Baptista Lucio, 2003). The contents evaluated in each opportunity were the following:

Assessment $\mathrm{N}^{0} 1$ : Previous concepts: properties of real numbers, Pythagoras Theorem.

Assessment $\mathrm{N}^{\mathrm{o}}$ 2: Functions, limits and continuity.

Assessment No3: Derivatives and applications.

Assessment $\mathrm{N}^{\circ} 4$ : Integrals and applications.

As examples, the first and the last assessments are shown in Figures 1 and 2. The assessments were prepared for Spanish-speaking students. The examples were translated for this paper. 
1. Write each of the following statements in words.

$\checkmark \mathrm{a}, \mathrm{b} \in \mathbf{R} \wedge \mathrm{a} \cdot \mathrm{b}=0 \Leftrightarrow \mathrm{a}=0 \vee \mathrm{b}=0$

$\checkmark a, b \in \mathbf{R} \Rightarrow(a+b)^{2}=a^{2}+2 \cdot a \cdot b+b^{2}$

2. Express the following property in symbols:

The nth power is distributed with the multiplication of real numbers

3. Graph the next property of the absolute value of a real number on a line

$$
|\mathrm{x}| \geq \mathrm{a} \Leftrightarrow \mathrm{x} \geq \mathrm{a} \vee \mathrm{x} \leq-\mathrm{a}, \mathrm{a} \in \mathfrak{R}
$$

4. The Pythagoras' Theorem states: In every right triangle the square of the hypotenuse is equal to the sum of the squares of the other two sides.

$\checkmark$ Represent the theorem graphically, showing the names involved

$\checkmark$ Express the theorem in symbolic form

Figure 1. First assessment

In the analysis of results, the students' performance was classified as follows:

- Satisfactory, when the requested activities are completed in a proper way.

- Quite satisfactory, when the student carries out half or more of the requested activities in a proper way.

- Unsatisfactory, when the student incorrectly solves all or most of the activities, or even does not solve them.

In all the assessments, two activities were proposed to analyze the communication in each register.

The graph of the function $y=f(x)$ is shown below.

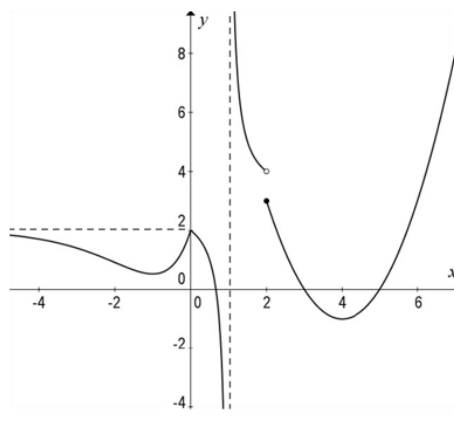

1. Express in symbols

The area of the enclosure in $[4,6]$

$\checkmark$ The improper integral in $[2,3]$

2. Shade the enclosures determined by the following integrals:

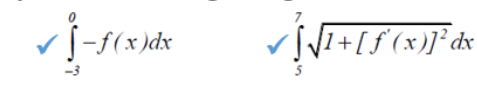

3. Explain, in words:

$\checkmark$ Why the Barrow's Rule cannot be applied in the interval $[-1,1]$

$\checkmark$ Why the integral of $y=f(x)$ in $[3,5]$ does not match the area of the enclosure of ordinates that determines that function, in the same interval.

Figure 2. Fourth assessment

Table 1 shows the criteria used to evaluate the degree of performance in the communication of the content using the natural register. In Table 2, the criterion 
with which the communication using the graphical register was evaluated; and in Table 3, the symbolic one was evaluated.

Finally, to analyze whether the students evolved in the communication of a statement, result or mathematical text considering three semiotic registers of representation (natural, graphical and symbolic), the obtained results in the four assessments were comparatively analyzed.

It should be noted that based on the errors detected in the first assessment, activities were organized to reinforce communication in the three registers, during the development of the contents of the subject.

Table 1. Criteria for evaluating the performance in communication in the natural register

\begin{tabular}{|c|c|c|}
\hline SATISFACTORY & QUITE SATISFACTORY & UNSATISFACTORY \\
\hline $\begin{array}{c}\text { The student properly } \\
\text { writes both statements in } \\
\text { words }\end{array}$ & $\begin{array}{c}\text { The student writes both } \\
\text { statements with a } \\
\text { predominance of natural } \\
\text { language but uses some } \\
\text { inappropriate terms }\end{array}$ & $\begin{array}{c}\text { The student writes } \\
\text { expresions without a } \\
\text { precise mathematical } \\
\text { sense, expresses it again } \\
\text { with symbolic } \\
\text { predominance or does not } \\
\text { answer }\end{array}$ \\
\hline
\end{tabular}

Table 2. Criteria for evaluating the performance in communication in the graphical register.

\begin{tabular}{|c|c|c|}
\hline SATISFACTORY & QUITE SATISFACTORY & UNSATISFACTORY \\
\hline $\begin{array}{c}\text { The student properly } \\
\text { obtains both requested } \\
\text { graphs }\end{array}$ & $\begin{array}{c}\text { The student properly } \\
\text { obtains one of the two } \\
\text { graphs and the other one } \\
\text { with not serious errors }\end{array}$ & $\begin{array}{c}\text { The student incorrectly } \\
\text { obtains the graphs or does } \\
\text { not answer }\end{array}$ \\
\hline
\end{tabular}

Table 3. Criteria for evaluating the performance in communication in the symbolic register.

\begin{tabular}{|c|c|c|}
\hline SATISFACTORY & QUITE SATISFACTORY & UNSATISFACTORY \\
\hline $\begin{array}{c}\text { The student writes } \\
\text { correctly both expressions } \\
\text { in symbols }\end{array}$ & $\begin{array}{c}\text { The student writes } \\
\text { correctly in symbols one of } \\
\text { the two expressions and } \\
\text { the other with not very } \\
\text { serious errors }\end{array}$ & $\begin{array}{c}\text { The student writes } \\
\text { expressions without a } \\
\text { precise mathematical } \\
\text { sense, uses inappropriate } \\
\text { symbols or does not } \\
\text { answer }\end{array}$ \\
\hline
\end{tabular}

Also, the errors made in the communication in each register, were grouped according to certain common characteristics. For the case of communication in natural language, the confusion of symbology and the use of imprecise expressions were observed. For the communication in the symbolic and graphic 
registers, the most observed errors were statements for particular cases or expressions without mathematical sense.

\section{Results and discussion}

To achieve the objective of the research: to analyze whether the first-year students of the FRSN-UTN of Industrial and Electronic Engineering specialties have improved the communication of a statement, result or mathematical text considering three semiotic registers of representation, the natural, the graphic and the symbolic, the results obtained by specialty, assessment and register are presented. Figures 3,4 and 8 show the distribution of students according to their performance in the different registers, in each of the four assessments (A1, A2, A3 and A4), separated by specialty. In these figures, the red, yellow and green colors represent that the students' performance in the communication in the corresponding register is unsatisfactory, quite satisfactory and satisfactory, respectively.

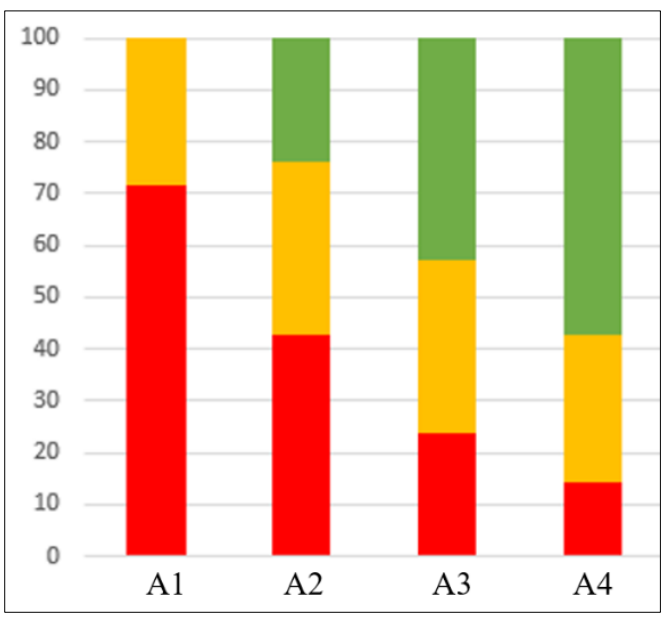

a) Electronic Engineer

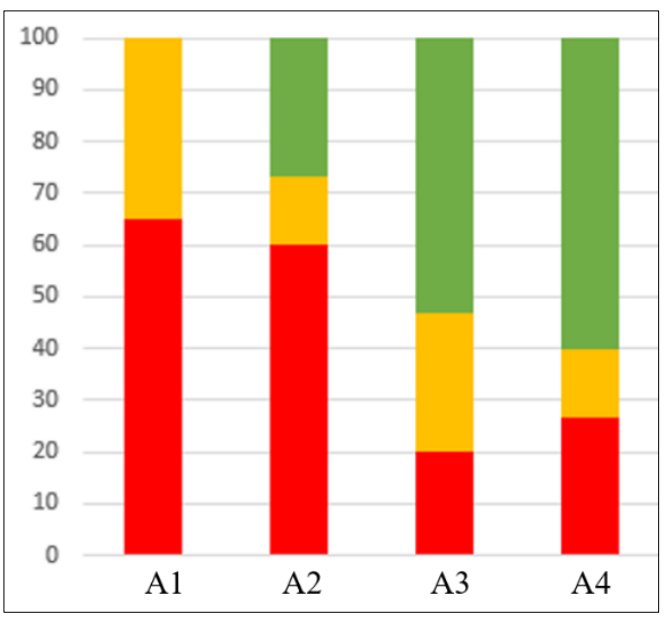

b) Industrial Engineer

Figure 3. Distribution of the students according to their performance in the communication in the natural register, in the four assessments

As can be seen in Figure 3, in the first assessment, no student of the analyzed specialties has shown a satisfactory performance in the communication using the natural register. Around $70 \%$ have had an unsatisfactory performance because they wrote expressions without a precise mathematical sense or restated it with a symbolic predominance. Several students of the two specialties confused the logical connective as the disjunction with the conjunction or the conditional with the biconditional.

It has also been observed that the majority used inappropriate expressions to refer to these last two as: "... this means that ...", "... at the same time ...", "... means that ..." or "... in the same way that ... " Another aspect to highlight is that no student has used the words "term" or "factor" to adequately refer to what the letters presented in the sentence represented in each case.

This situation was improving throughout the following assessments and the initial situation was reversed, obtaining approximately $60 \%$ satisfactory 
performance in the fourth assessment, for the two specialties. However, it is worthy to mention that the errors detected in the second assessment regarding this register were due to the fact that the majority continued to write expressions without a precise mathematical sense. This situation was also evidenced in the third assessment, when they were asked to infer about certain characteristics of the function from the analysis of the graph of its derived function. Also observed throughout the four assessments were several responses with single words that show the inability of some students to write complete sentences. Although this situation improves in the fourth assessment, the comment about the poor writing style that they manifested throughout the four assessments and the spelling mistakes they made cannot be ignored.

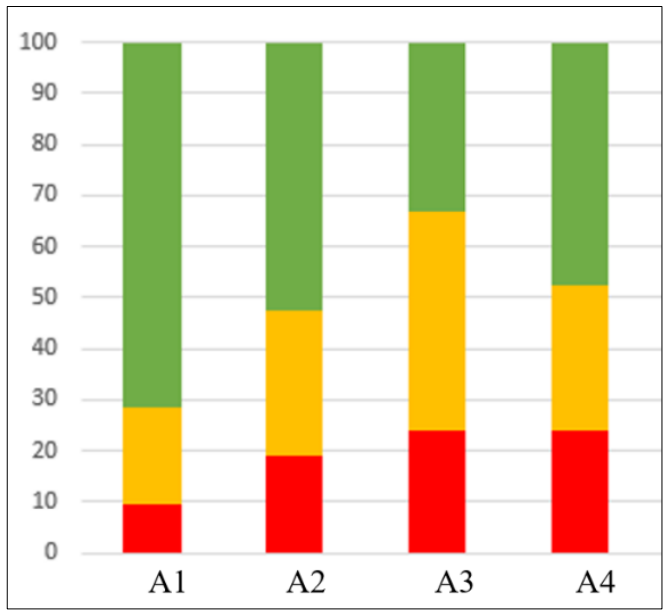

a) Electronic Engineer

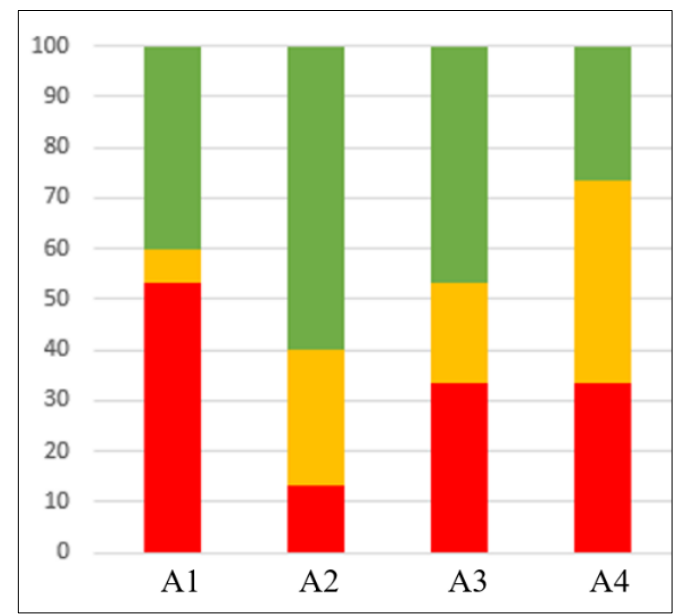

b) Industrial Engineer

Figure 4. Distribution of the students according to their performance in the communication in the graphical register, in the four assessments

Regarding the communication using the graphical register, it can be seen in Figure 4 that the performance of the students of Electronic Engineering showed percentages of unsatisfactory results that did not reach $10 \%$ in the first assessment, but they were increasing until being located in the $23.80 \%$ in the last two assessments. This behavior throughout the four assessments is not alarming considering that the final obtained percentage from unsatisfactory results is close to $20 \%$.

On the other hand, as shown in Figure 4, Industrial Engineering students, although their best result in the communication using the graphical register was obtained in the second assessment, a significant improvement was observed, going from $53.33 \%$ of unsatisfactory results in the first to $33.33 \%$ in the last two.

In the first assessment, the unsatisfactory results of the students of Electronic Engineering were exclusive due to the fact that they did not complete the answers while those of the other specialty were also generated because they confused the property that they had to graphically represent or not to graph for a generic value as requested. Between $10 \%$ and $20 \%$ of Industrial Engineering students confuse the stated property or they do not graph for a generic "a" value for the case of item 3. Examples of these types of errors are shown in Figure 5. 


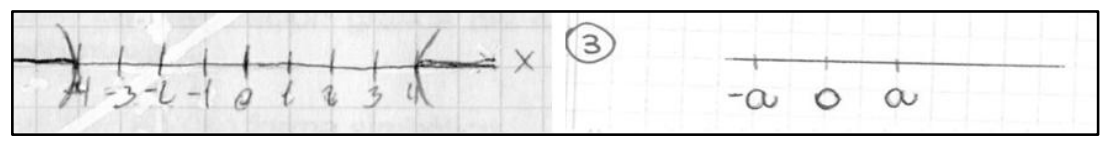

Figure 5. Examples of graphs considering a particular case and discarding the equal or considering the property with the equal

However, after having worked graphical communication throughout the year, it is worth emphasizing that many students of the two specialties still present serious errors that show total ignorance about the graphical representation of limits or functions that do not verify a certain theorem related to derivatives or integrals. Some examples are shown in Figure 6. Notwithstanding the results obtained for communication in this register, some students who were unsuccessful in the first assessment were improving throughout the course and achieved a satisfactory performance in the last one, in terms of graphic language. Figure 7 presents some examples of correct answers from students that failed the first assessment.

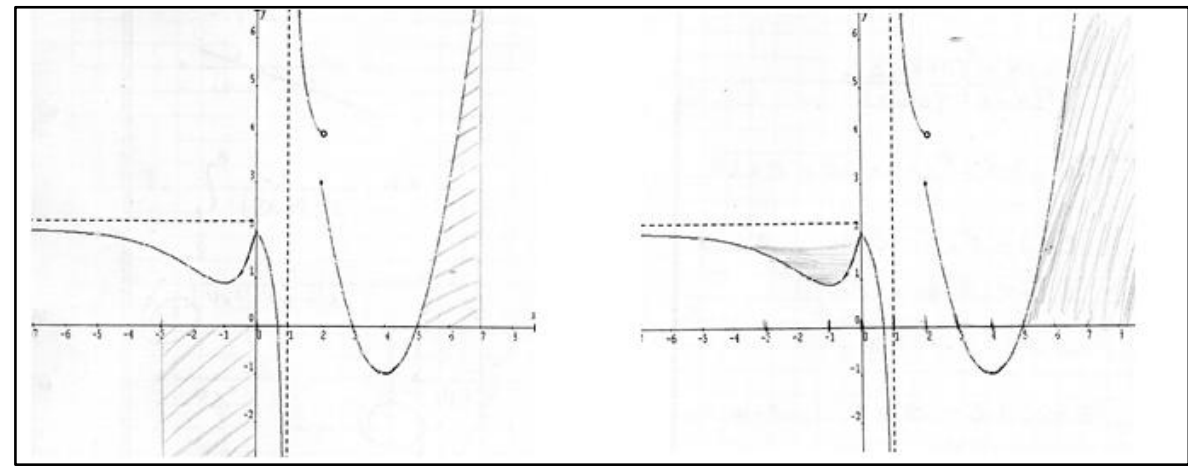

Figure 6. Examples with communication problems in the graphic language

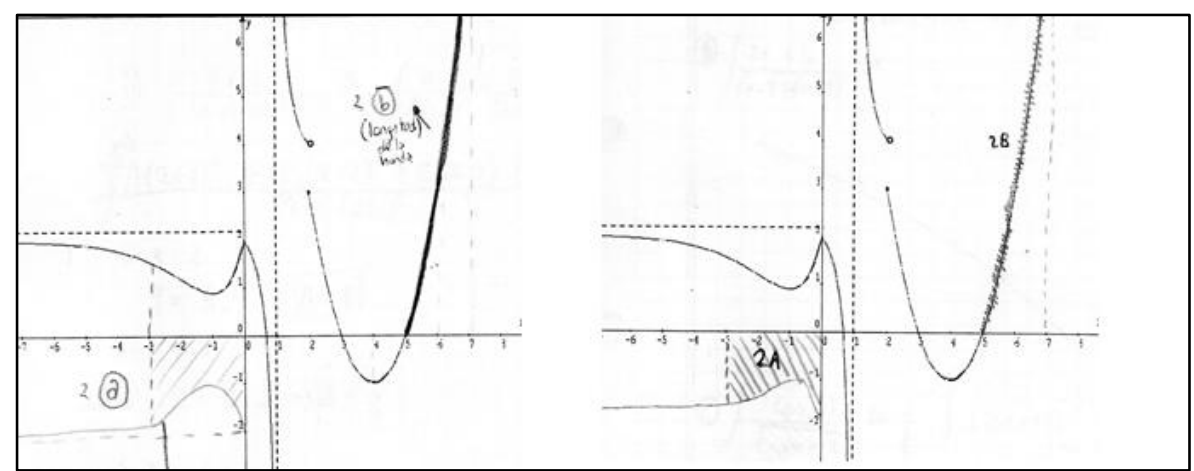

Figure 7. Correct answers from students that failed the first assessment 


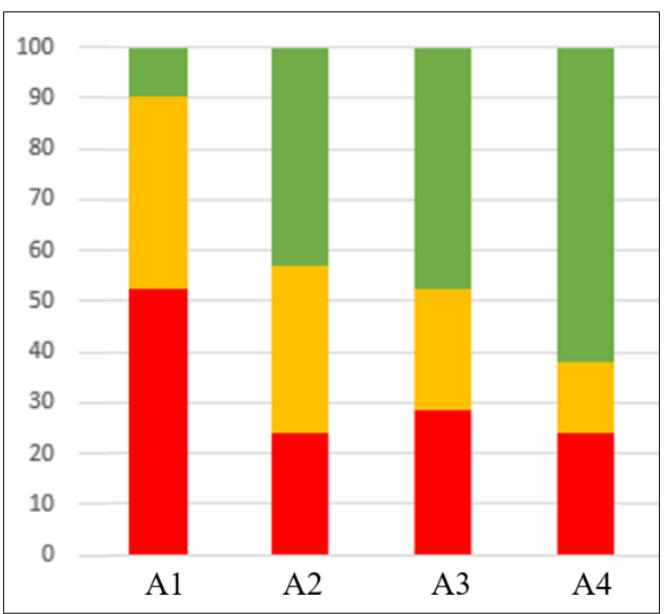

a) Electronic Engineer

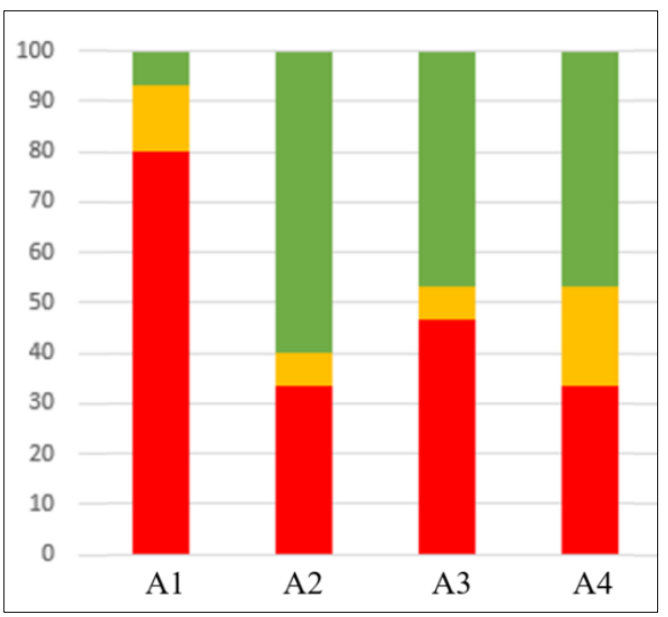

b) Industrial Engineer

Figure 8. Distribution of the students according to their performance in the communication in the symbolic register, in the four assessments

In Figure 8, communication performance using the symbolic register can be observed, exhibiting a situation very similar to what was commented for the natural register. The unsatisfactory performance of the students of Electronic Engineering decreased from $52.38 \%$ in the first assessment, to $23.80 \%$ in the last one. For those students of Industrial Engineering, which began with a percentage of $80 \%$ of unsatisfactory results, improved and happened to settle around $30 \%$ in the remaining assessments.

Regarding the common errors observed in the communication in the symbolic register of the first assessment, it is to emphasize that several students of the two specialties, wrote the property presenting a particular case instead of writing it in a general way as requested (Figure 9) and it is even more the number of students who wrote expressions in symbols without mathematical sense (Figure 10).

$$
\text { 2) }(a \cdot b)^{10}=a^{10} \cdot b^{10} / a, b \in \mathbb{R} \quad 2-a, b \in \mathbb{R} \Rightarrow(a \cdot b)^{11}=2^{11} \cdot b^{11}
$$

Figure 9. Examples of the property presenting a particular case

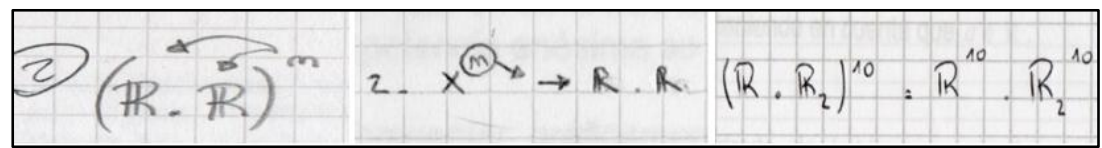

Figure 10. Examples of expressions without mathematical sense to express the property

Also, a significant number of students have improperly used some logical symbols such as quantifiers. It seems that they use them as a way to abbreviate writing and not with their true function. 
This type of errors decreases in the remaining assessments, but without disappearing (Figure 11).

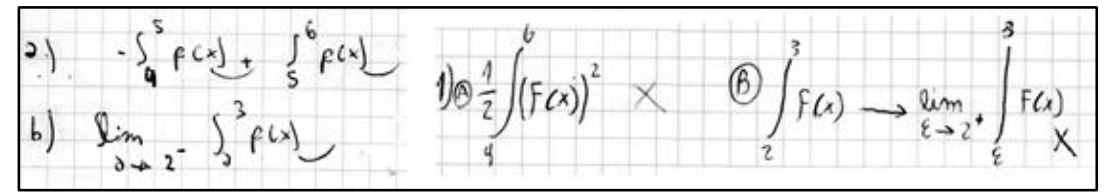

Figure 11. Examples where students do not use the correct notation for integrals

Some students who were unsuccessful in the first assessment, achieved a satisfactory performance in the last one, in terms of symbolic language. Some examples of correct answers from students that failed the first assessment are presented in Figure 12.

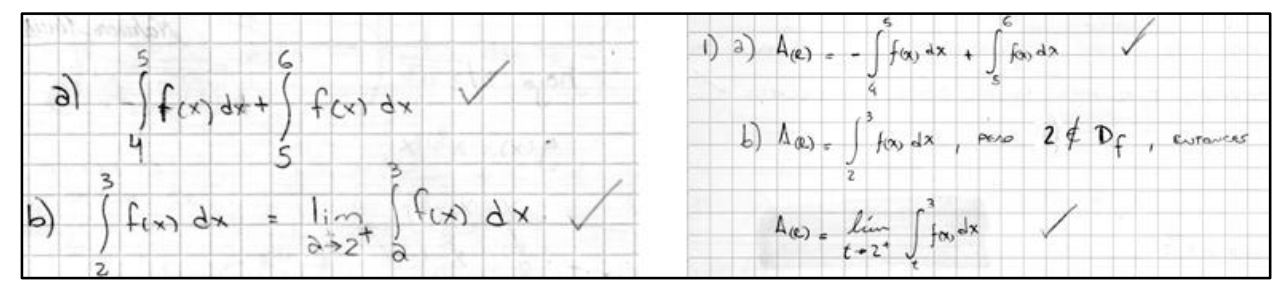

Figure 12. Correct answers from students that failed the first assessment

Finally, it is interesting to highlight that throughout the four assessments several responses were observed from students of the two specialties accompanied with graphics, despite the answers were requested in both the natural and the symbolic register. Although the graphics, in many cases, did not agree with the written paragraphs. This leads to think that despite not being requested, they draw upon the graphic register as a tool for the construction of their answers. In part, it is consistent with the preference register of the first-year students in those engineering, previously analyzed (Romiti, Sgreccia, Caligaris, 2014).

\section{Conclusion}

The obtained results clearly show that the Engineering students who start studying calculus in one variable at FRSN-UTN in the Electronic and Industrial specialties have serious deficiencies while expressing themselves in the symbolic language, typical of mathematics, and in the natural. In the first assessment, the difference of origin of the students of technical and non-technical high schools was only evident in the work on the graphic register since in the other two, the results were very similar and with errors in common.

Although during the first semester the results were alarming in the three registers of representation, mainly for Industrial Engineering, it can be seen that during the second semester the number of unsatisfactory starts to decrease, finishing both courses with small differences. The authors of this paper consider that the intensive work that was carried out with the students to reverse the first results was largely responsible of the improvements. 
Finally, it can be concluded that it is possible to improve the quality of communication of first-year university students, incorporating in the teaching process activities oriented not only to natural communication, but also related to the availability and use of other systems of semiotic representation essential for the student to understand and communicate a mathematical object or idea effectively.

This study has same limitations, to be considered for future research. It assesses a specific group of first-year students within specific specialties: two are analyzed while there are five different ones. The behavior of other students may be different from what was discussed in this article. We have taken the first step, assessing first year students in one of the mathematics that they study, calculus in one variable. We will continue deepening the analysis of the students' communication competence in Mathematics, particularly analyzing Algebra and Analytical Geometry and Calculus simultaneously.

It is possible that, reorienting the teaching practices in the two subjects articulated horizontally, better results in less time could be obtained.

Teachers are counsellors and accompany the development of skills and not just discuss content, looking for new instruments for this purpose. It is not easy to change the way to assess, but accomplish students' progress in their communication is worth the effort.

\section{References}

Cubero, S. N. (2017). Essential Communication Skills for Engineers, Scientists and Multidisciplinary Teams. International Journal of Information and EducationTechnology, 7 (7), 483-494. https://doi.org/10.18178/ijiet.2017.7.7.917

Davis, M. T. (2010). Assessing Technical Communication within Engineering Contexts Tutorial. IEEE Transactions on Professional Communication, 53, pp. 33-45. https://doi.org/10.1109/tpc.2009.2038736

Deveci, T. (2019). Interpersonal Communication Predispositions for Lifelong Learning: The Case of First Year Students. Journal of Education and Future, 15, 77-94. https:// doi.org/10.30786/jef.358529

Díaz, H. (2009). El lenguaje verbal como instrumento matemático. [Verbal language as a mathematical instrument]. Educación y Educadores [Education and Educators], 12 (3), 13-31.

Duval, R. (2004). Semiosis y pensamiento Humano. Registros semióticos y aprendizajes intelectuales. [Semiosis and human thought. Semiotic registers and intellectual learning]. Cali: Universidad del Valle.

Duval, R. (2006). A cognitive analysis of problems of comprehension in a learning of Mathematics. Educational Studies in Mathematics, 61, 103-131. doi.org/10.1007/s10649-006-0400-z

Gallardo-Echenique, E., Bullen, M., Marqués-Molías, L. (2016). Student Communication and Study Habits of First-year University Students in the Digital Era. Canadian Journal of Learning and Technology, 44 (1), http:/ / dx.doi.org/10.21432/T2D047

Gebre, E. (2018). Learning with Multiple Representations: Infographics as Cognitive Tools for Authentic Learning in Science Literacy. Canadian Journal of Learning and Technology, 44 (1), http://dx.doi.org/10.21432/cjlt27572 
Giordano Lerena, R. \& Compilador. (2016). Competencias genéricas de egreso del ingeniero argentino [Generic egress competencies of the argentine engineer] In Competencias $y$ perfil del ingeniero iberoamericano, formación de profesores y desarrollo tecnológico e innovación. [Competencies and profile of the Ibero-American engineer, teacher training and technological development and innovation]. Bogotá, Colombia: ARFO Editores e Impresores Ltda.

Giordano Lerena, R. (2018). Diseñando los nuevos estándares de acreditación de carreras de ingeniería en Argentina. [Designing the new standards of accreditation of engineering careers in Argentina]. In Luis Alberto González Araujo (Ed.), Aseguramiento de la calidad y mejora de la educación en Ingeniería: Experiencias en América Latina. [Quality assurance and improvement of engineering education: Experiences in Latin America]. (pp. 75-101). Colombia: Opciones Gráficas Editores Ltda.

Gynnild, V. (2016) Task design for improved learning in science and engineering: a principled approach. In L. Gómez Chova, A. López Martínez, I. Candel Torres (Eds.), ICERI2016. Proceedings of the 9th Annual International Conference of Education, Research and Innovation (pp. 7973-7978). Sevilla, España.

Hernández Sampieri, R., Fernández Collado, C., \& Baptista Lucio, P. (2003). Metodología de la investigación. [Research methodology]. México DF: McGraw Hill.

Kumar, S., Hsiao, J. K. (2007). Engineers Learn "Soft Skills the Hard Way": Planting a Seed of Leadership in Engineering Classes. Leadership and Management in Engineering, 7 (1), 18-23. https://doi.org/10.1061/(asce)1532-6748(2007)7:1(18)

Nadeem, M., Blumenstein, M., Biglari-Abhari, M. (2018). Exploring the Impact of in Class Writing Exercises in an Engineering Course. In Lee, Nikolic, Ros, Shen, Lei, Wong, Venkatarayalu (Eds.), Engineering Next-Generation Learning. Proceedings of 2018 IEEE International Conference on Teaching, Assessment, and Learning for Engineering (pp. 624-631). Wollongong, NSW, Australia. https://doi.org/10.1109/tale.2018.8615411

Palma, M., de los Ríos, I., Miñán, E. (2011). Generic competences in engineering field: a comparative study between Latin America and European Union. Procedia Social and Behavioral Sciences, 15, 576-585. https://doi.org/10.1016/j.sbspro.2011.03.144

Pimienta Prieto, J. (2012). Las competencias en la docencia universitaria: preguntas frecuentes. [Skills in university teaching: frequently asked questions]. México: Pearson Educación.

Romiti, M., Sgreccia, N. y Caligaris, M. (2012). Desempeño de los alumnos en el estudio del concepto de límite. [Performance of the students in the study of the limit concept]. Conference proceedings of The XVII National and IX International Encounter on Mathematics Teaching in Engineering Careers. Retrieved from http://emci.edu.ar/anales-de-encuentros/\#2012

Romiti, M.R., Sgreccia, N., \& Caligaris, M.G. (2014). Preferencia de registros de representación en el concepto de límite de funciones de alumnos de primer año de Ingeniería. [Preference of representation registers in the concept of limit of functions of students of first year of Engineering]. Acta Latinoamericana de Matemática Educativa [Latin American Act of Educational Mathematics], 27, 11071115. México: Comité Latinoamericano de Matemática Educativa. [Latin American Committee on Educational Mathematics] Retrieved from https://clame.org.mx/uploads/actas/alme27.pdf

Sierpinska, A. (2013). Understanding in Mathematics. Hoboken, NJ: Taylor and Francis.

Szilárda, S., Benedeka, A., Ionel-Cioca, L. (2018). Soft Skills Development Needs and Methods in Micro-Companies of ICT Sector. Procedia - Social and Behavioral Sciences, 238, 94-103. https://doi.org/10.1016/j.sbspro.2018.03.012 